\title{
Gerencia pública del trabajo y crecimiento del empleo independiente*
}

\author{
Díaz, Luis Eduardo**
}

\section{Resumen}

Se describen los cambios que la gerencia pública del trabajo debe asumir por el aumento del empleo independiente, partiendo de la hipótesis que las decisiones planteadas dependen de que el Estado pueda superar severos condicionantes que limitan su accionar, cada vez más reducido. Siguiendo un enfoque metodológico cualitativo descriptivo y requiriéndose de la contextualización por el lado de la administración previsional; se constata que pese al número de iniciativas disponibles, la gerencia del trabajo, adoptó una reforma uniforme sin logros satisfactorios. Sin embargo, países que no lo hicieron, obtuvieron resultados similares, por rígidos condicionantes en curso, tales como la incursión a la economía mundial; la crisis de lo colectivo; la no inclusión de la seguridad social en la agenda partidista; y la falta de una gerencia propia y especializada. Se concluye que la seguridad social no es un programa neutral y que las mejoras gerenciales sólo serán posibles al superarse tales restricciones. Por su parte, el Ministerio del Trabajo, como ente principal, a causa de la contracción del mercado, pierde significado e importancia, pues las políticas públicas se desplazan prioritariamente a otros programas de tipo asistencial.

Palabras clave: Seguridad social, administración del trabajo, trabajo informal, empleo independiente, gerencia pública.

\section{Public management of work and increase in independent employment}

\section{Abstract}

Changes in public labor management which must be assumed due to the increase in independent labor are described, beginning with the hypothesis that the decisions proposed are dependent upon whether or not the state can overcome the severe conditions which limit its sphere of activity which is continually being reduced. By following a descriptive, qualitative methodological focus, which

Recibido: 04-09-02. Aceptado: 05-01-17

* El autor agradece el patrocinio del CONDES de la Universidad del Zulia (LUZ). (Proyecto Demandas Sindicales en Seguridad Social).

** Profesor Titular de la Universidad del Zulia (LUZ). Facultad de Ciencias Jurídicas y Políticas. E-mail: luisediaz@intercable.net.ve. 
requires the contextualization of provisional administrative aspects, it was determined that even when there were a large number of possible initiatives, labor management adopted a uniform reform process without satisfactory achievement. However, the countries that did not change, obtained similar results due to prevalent rigid conditions such as entry into the world economy, collective crisis, the non-inclusion of social security in party agendas, and the lack of adequate specialized management. The conclusion is that social security is not a neutral program and that better management will only be possible when these restrictions are overcome. On the other hand, labor ministries as guiding entities, due to the contraction of the market, lose their significance and importance, since public policies are shifted to other types of assistance programs.

Key words: Social security, labor administration, informal labor, independent employment, public management.

\section{Introducción}

La gerencia pública del trabajo tiene una especificidad que le es propia, es una identidad que es adquirida por el reconocimiento de la convención colectiva como fuente de derecho; la organización obrera que la motoriza; y la dependencia jurídica que es la nota distintiva del contrato del trabajo, pero también es cierto que la misma soporta una crisis muy particular; debe sortear las dificultades de un mercado de trabajo que no produce empleos suficientes; no halla personal calificado; y una buena parte de los destinatarios potenciales de sus ejecutorias son trabajadores independientes. Tradicionalmente, estos trabajadores por cuenta propia no orbitan por la administración laboral, no tienen nada que declarar, ni beneficios que hallar en el entramado administrativo. Son asimismo contados los casos de afiliación obligatoria de los independientes (Argentina, 1994 y Uruguay en 1996), pero ello no pasa de ser una formalidad.

Los autónomos deben cotizar la parte del empleador y en el sector infor- mal no están cubiertos, ello se traduce en desprotección, sub-declaración o conductas evasoras. En los demás casos, donde la afiliación es voluntaria, la misma es escasa o nula, salvo por algunos segmentos reglamentados, -como en Panamá-, para billeteros, conductores de taxi, expendedores del mercado público, o como en Venezuela; para cooperativistas, costureras, y trabajadores de la cultura. Sin embargo, ello no se ha traducido en una mejora para los diferentes grupos y tampoco los programas de afiliación se han popularizado.

La protección desciende y el principal empleador es el sector no estructurado, así tenemos como en América Latina, el nivel promedio de cobertura de la seguridad social, en relación con la Población Económicamente Activa (PEA), es de un $42 \%$ (OIT, 1999); ha aumentado el desempleo abierto en un $9 \%$; y el trabajo independiente pasó de un 22 al $25 \%$ en el sector informal (OIT, 2001). Europa confronta igualmente estos problemas, aunque algunas causas son comprensiblemente diferentes, entre las que se encuentran, siguiendo a Sarfati (2003): 
1. La transición en la que se encuentra la sociedad hacia una post-industrial que ensancha el sector servicios y captura desempleados ofreciéndoles puestos precarios.

2. Por la globalización, que exacerba la competencia y la movilidad de capital hacia lugares de bajo costo y bajos impuestos, frenando las posibilidades de aumento de financiamiento de la seguridad social (en el caso de Latinoamérica la misma causa tiene otra consecuencia; la de generar empleos inseguros o precarios) y

3. Por el aumento de los empleos atípicos (trabajos temporales, a medio tiempo, de independientes o cuasi-independientes), los que ocupan la tercera parte de la población económicamente activa de la Unión Europea, concentrándose en mujeres, jóvenes y personas de avanzada edad.

Al volver nuestra mirada a América Latina, una buena parte del mercado está constituido por independientes informales a los que una gerencia pública -ya con una buena parte de problemas estructurales aún sin resolver-; debe encarar para asegurarles, -en obsequio de la justicia social-; algún porvenir. Estos trabajadores tienen menos oportunidad de consu- mo y no tienen posibilidad de generarlo en el futuro; apenas si pueden sobrevivir con algún dinero para necesidades que no llegan a satisfacer el alimento ${ }^{1}$.

Forzoso es entonces que; primero, la administración mejore trámites y procedimientos en sus sedes judiciales (tribunales) y administrativas (inspectorías, procuradurías, cajas, institutos autónomos), segundo, es que evite relaciones contractuales simuladas bajo el ropaje del civilismo o de figuras mercantiles, procediendo a declarar como nulas las contrataciones fraudulentas ${ }^{2}$. Sin duda que la simulación pretendería oscurecer la subordinación jurídica como eje definitorio del contrato de trabajo ${ }^{3}$.

Partiendo de este contexto y orientación preliminar, se sigue en el presente documento un enfoque metodológico cualitativo descriptivo de los cambios que la gerencia laboral y previsional debe asumir a raíz del crecimiento del trabajo autónomo, lo que sería posible en el supuesto que reconozca su propia capacidad de cambio, analizando las reformas habidas junto con las posibilidades de transformación de la gerencia para ofrecer un mejor servicio a potenciales usuarios independientes.

1 La OIT (2000:307) en el informe sobre el trabajo en el mundo, señala que el 44\% de la población venezolana vivía por debajo de la frontera de la pobreza con 1 dólar al día, el 11,8\% y con 2 dólares al día, el 32,2\% (en \$ p.p.a. de 1985).

2 La simulación del contrato de trabajo se entiende como el encubrimiento deliberado del patrono de la relación de trabajo (atribuyéndole carácter civil o mercantil) para, de este modo, evadir los deberes que dimanan de la legislación laboral y de la seguridad social (Carballo, 2002: 69).

3 La subordinación en su sentido jurídico se entiende como el poder de dirección que el contratante tiene sobre el empleado. 


\section{Impacto de las nuevas modalidades de empleo en la administración del trabajo}

Cuando emergen las relaciones industriales y la seguridad social como disciplinas científicas, la administración del trabajo adquiere singular importancia ${ }^{4}$. Estructurar el sistema de relaciones industriales y de seguridad social, requería de una dirección y campo especializado: El derecho colectivo del trabajo, pondría su contribución para profundizar esa autonomía. En lo que respecta al derecho de la seguridad social, éste se encargaría de regular las secciones de administración, prestaciones y financiamiento surgidas de las relaciones obrero-patronales.

Por el lado de la previsión social, los institutos centrales, las cajas de previsión, mutualidades y administradoras; conformarían un abanico muy extendido de acción directa. Y el área de la salud, aunque tomó derroteros distintos e independientes, en razón de la singularidad del acto médico; cuenta aún con canales de comunicación abiertos y expeditos con la previsión social. Empero, la nota más resaltante de esa especificidad de la administración laboral; es que siendo potencialmente conflictiva, participa el
Estado con los demás actores, produciendo un conjunto normativo derivado del tripartismo, a la vez producto de la necesidad de la paz laboral y la ansiada gobernabilidad.

Pero el arquetipo legal se vería afectado cuando el papel del Estado como protagonista y su instrumental normativo, comienza a desparecer; cae la negociación colectiva, se cuestionan los costos de los sistemas públicos y se acusa al tripartismo de inefectivo.

Después de la fase expansiva del capitalismo, gobiernos y empresas han tenido que adaptarse a los cambios que se producen en el mercado de trabajo. Aunque la cobertura debe ser universal, como postula la seguridad social, la segmentación es evidente: Diversos tipos de contratos surgen a despecho del contrato por tiempo indeterminado, la inspección del trabajo es irregular o baja, y la administración, particularmente la previsional, es sumamente lenta. $Y$ si bien la seguridad social ha contribuido históricamente al fortalecimiento de la administración de la cosa pública laboral, debe enfrentar agudos desniveles de atención.

La dependencia que generó la industria y que modeló el tipo de contrato y el objeto de la disciplina laboral, donde el trabajador ocupaba un espacio en la em-

Con la segunda guerra mundial, los estudios empresariales y sindicales confluyen para maximizar la producción, minimizar las huelgas y evitar la inflación. De este modo, en los años cuarenta se crean licenciaturas de relaciones industriales en varias universidades norteamericanas y desde 1948, la Asociación de Estudios sobre Relaciones industriales (IRRA) congrega a expertos en congresos y publicaciones (Kochan citado por Ojeda, 1995: 56). En lo que respecta a la seguridad social como disciplina científica, su nacimiento coincide con su univerzalización a partir de la Declaración de Filadelfia de 1944 de la OIT (Almansa, 1989). Por su parte, la Asociación Internacional de Seguridad Social (AISS) reúne a 363 instituciones de 142 países (Verstraeten, 2002). 
presa a las órdenes del patrono y se involucraba en procesos técnicos particulares, comienza a cambiar cuando la producción se descentraliza, la competencia se globaliza, nuevas tecnologías desplazan a trabajadores fijos y el desempleo, es una variable preocupante que empieza a generar cambios en las legislaciones, las que se hacen menos sociales y más productivas; menos proteccionistas y más generadoras de empleo, aunque sin reparar en los resultados futuros. Contratos a medio tiempo, temporales, contratos de formación y el incremento del trabajo a domicilio, serán las nuevas formas de contratación (Córdova, 1997).

Estas mutaciones han afectado a la administración del trabajo de manera muy sensible: Dado que los Ministerios ejecutan labores menos relevantes, los presupuestos tienden a disminuir. Esto ocurre porque los trabajadores se informalizan; los empresarios arbitran soluciones propias e internas; y las unidades son oficinas gestoras, de registro y escasa supervisión, en fin; el Ministerio pierde significado social y político, pues el centro de gravedad de las políticas públicas se desplaza a otros programas de tipo social y asistencial, más urgentes e inmediatos, y con una fuerte dosis de intervención gubernamental. Además, al ser la cobertura menor, el financiamiento se resiente y las condiciones de trabajo precarias no pueden ser controladas ni evitadas, aumentando el círculo perverso de desprotec- ción que se traslada igualmente a la población en edad de retiro.

\section{Contexto en el que se desenvuelve la gerencia pública}

La incorporación a la economía mundial bien podría destruir prestaciones sociales a cambio del puro salario de subsistencia, sin licencias ni seguros, y sin arrastrar nunca las empresas pesados fardos laborales en sus balances. La aparente rigidez del pago de prestaciones periódicas, se substituye con salarios medidos por hora, desapareciendo el típico contrato laboral, por salarios precarios, según el tipo de trabajo y empresa ${ }^{5}$.

Es un hecho que estos contratos temporales ponen a prueba la existencia del derecho del trabajo, algunos de los cuales, apenas empiezan a ser reconocidos en la legislación (Raso, 2003).

En el caso venezolano -que puede servir de ejemplo general-, el Estado se ha preocupado en atender los asuntos previsionales desde el seguro social para los trabajadores del sector privado, sin que la franja de cobertura haya aumentado hacia otros segmentos desprotegidos. Ello ocurrió en buena medida; porque los salarios perdieron su poder de compra (OIT, 2001); la estabilidad en el empleo no fue la misma; y el crecimiento no fue constante, el seguro social en consecuencia, no podía menos que resentirse, mientras, la legislación laboral incorpora-

Según un informe del Ministerio de Trabajo y Seguridad Social español (citado por Abellán, 2001), laborar con un contrato temporal incrementa las posibilidades de sufrir un accidente. En España, la temporalidad afecta al 31,6\% de los trabajadores, asegurándose que el riesgo de accidentes es tres veces mayor en relación con los enganches indefinidos. 
ba el contrato a tiempo parcial en el artículo 194 de la Ley Orgánica del Trabajo (Congreso de la república,1997) y en su reglamento, (Presidencia de la República,1999), las empresas de trabajo temporal (artículos 23 al 25).

Aparte, existe una crisis de lo colectivo, la que sin duda afecta a la administración del trabajo, esta crisis, se traduce en falta de credibilidad, menguados recursos y baja capacidad de respuesta. Aparece una desunión entre lo particular y lo social, el interés de uno se superpone al interés colectivo, que es muy tenue o vago. El propio trabajador independiente es presa del individualismo. El autoempleo le permite aislarse, despreocuparse por el uso de instalaciones o servicios a los que rara vez acude, aún más; esas relaciones con la administración del trabajo, suelen estorbarle en sus propósitos de obtener o mantener un empleo, cuando intenta liberarse de tasas y supervisiones legales.

Además de la globalización económica y de la crisis de identidad por la que atraviesa "el nosotros"; la ley, que suele regular todo el proceso asegurativo, impone a los trabajadores independientes, condiciones extras o reenvía su tratamiento a reglamentos donde el músculo administrativo del Estado se desarrolla rara vez.

La presión política para incluir a los trabajadores autónomos no es muy fre- cuente, inclusive; que los partidos elaboren una agenda de seguridad social y la discutan abiertamente, es anormal. El debate, cuando lo hay, es desbordado por los acontecimientos -normalmente medidas de ajuste general que deben adoptarse-; por lo que el programa asegurativo forma parte de una reforma macroeconómica más urgente. Y aunque la seguridad social es todo un cuerpo codificado que permite adoptar diferentes acciones debidamente soportadas, obedece su adopción interesada a fórmulas prefabricadas, a cambio de un préstamo internacional requerido para la macro reforma.

El programa de seguridad social, pocas veces explícito, es realizado por un grupo profesional que no pertenece a la administración. La experiencia recabada de las reformas previsionales en América Latina, da cuenta que tal grupo es contratado en paralelo por la administración, pues carece de los recursos adecuados; o no tiene su burocracia experticia en el tema, sobretodo, cuando se trata de incorporar la fórmula del ahorro obligatorio, lo que implica novedades y ajustes muy serios, de compromiso, vigilancia y gestión 6 .

Dicha perspectiva puede estar cambiando, a raíz del pobre impacto social de las reformas, y por la repercusión que el tema previsional tuvo y todavía

La política social es un mecanismo efectivo de clientelismo político del estado corporativo, en donde los organismos e instituciones encargadas de esta función, formulaban e implementaban una política social que tampoco promovía la equidad ni la eficiencia, pero que las atenuaba. En la mayoría de los países latinoamericanos existe una desconexión entre la presupuestación, planificación de inversiones, sistemas de procuración, aplicación de los recursos financieros y la evaluación de los resultados, los cuales muestran todavía muchas limitaciones y deficiencias (Vargas, 2001:42). 
conserva en las doctrinas de la iglesia católica (por la solidaridad que ambas postulan), o en la socialdemocracia (por el laborismo británico que dio origen a la universalización previsional), o por la denominada "tercera vía".

Precisamente, el primer Ministro inglés, Tony Blair, anunció la extensión de las Ilamadas Job Centre Plus, un moderno sistema de oficinas de empleo que quiere tratar a sus usuarios como clientes, como empleados en potencia, más que como parados en busca de trabajo. Sin embargo, quienes rechacen las ofertas de empleo corren el riesgo de perder los subsidios. Para que ese modelo funcione "se tiene que basar en la mutua responsabilidad", recordó Blair en clara alusión a los ajustes del Estado de Bienestar que ha venido predicando, que no es un derecho universal, gratuito e ilimitado; sino un instrumento puntual para ayudar a los más necesitados, acercándose así más al modelo norteamericano que al tradicional Estado asistencial centroeuropeo. Fue precisamente Blair, quien en el Parlamento francés, en 1998, enfatizó que "no existen en la economía globalizada de hoy, derechas o izquierdas, sino buena o mala gestión del espacio público" (Oppenheimer, 2002).

Señala al respecto Vicenç Navarro (2002) que desde esta versión modernizadora de la socialdemocracia, la buena gestión de las políticas económicas y sociales incluye algunos elementos heredados del pensamiento neoliberal y/o conservador, tales como el rechazo de políticas redistributivas de carácter universal -que se asume antagonizan a la clase media-, y que garantizan derechos sociales, civiles y económicos a toda la ciuda- danía, siendo sustituidas por políticas asistenciales, orientadas hacia la prevención de la exclusión social y la pobreza, facilitando la integración de los grupos vulnerables a la clase media, mediante programas de igualdad de oportunidades que se centran primordialmente en dar más becas y más formación profesional a jóvenes de familias humildes.

En esta estrategia, las políticas expansivas encaminadas a ofrecer seguridad a toda la población, características de las tradiciones socialdemócratas, son sustituidas por políticas de oportunidad, las que son al mismo tiempo menos costosas, permitiendo así reducir los impuestos, lo que es una propuesta ampliamente extendida en la socialdemocracia modernizada que excluye al mismo tiempo cualquier política de gasto público expansivo, acentuando en su lugar la necesidad de reducirlo, a fin de integrarse monetaria y económicamente a la Unión Europea.

La globalización fuerza a los Estados a seguir políticas económicas y sociales parecidas, diluyendo así el significado de izquierda y derecha, siendo esta dicotomía sustituida por otra en que la mayor diferencia entre un gobierno $u$ otro no es que sea de izquierda o de derecha, acaso que sea buen o mal gestor de lo público.

A los sindicatos por su parte, se les permitió intervenir en la administración pública. Este rozamiento de cúpulas ocurrió; porque los gremios se interesan por un tema que le es propio; y porque después de la segunda guerra mundial, el Estado les facilita dicha intervención, dado que los necesitaba como garantía de gobernabilidad. El denominado neocorporatismo obedece al papel que el Estado tendría en la economía, la centrali- 
zación política y la masificación productiva, presentándose así como el portador de los intereses generales (Ojeda, 1995: 44-45).

\section{El trabajo independiente y las dificultades de la administración para su registro}

La diferencia esencial que existe entre el trabajo dependiente, subordinado o por cuenta ajena y el trabajo autónomo, radica en la ajenidad o propiedad que el trabajador tiene respecto de los frutos que se obtienen de su esfuerzo laboral. El trabajador autónomo adquiere los resultados de su trabajo y luego puede transferirlos a terceros mediante otros tipos de contratos. Los riesgos inherentes al trabajo y a la colocación de sus frutos son del trabajador (Pérez Botija, citado por Gumucio, 2000: 9). Se labora por cuenta propia y bajo riesgos auto asumidos. De ahí la denominación de trabajadores por cuenta propia opuesta a la de trabajadores por cuenta ajena.

Es importante tener presente que los trabajadores autónomos son sólo parte -si bien relevante- de un mundo laboral más amplio, denominado sector no estructurado. En este sentido, se ha propuesto por la OIT (citada por Gumicio, 2000:7), una clasificación en seis categorías: 1) Trabajadores por cuenta propia, los cuales trabajan solos o con familiares no remunerados, que no perciben un salario, pero ganan dinero. 2) Propietarios o empleadores de microempresas, con unos pocos aprendices y trabajadores contratados. 3) Jornaleros asalariados, empleados por microempresas, normalmente sin contrato, que trabajan de vez en cuando o de modo estable. 4) Trabajadores familiares que no perciben un salario. 5) Trabajadores asalariados, que eligen ellos mismos su lugar de trabajo, por ejemplo su domicilio; y 6) Trabajadores domésticos remunerados.

Por su parte, Daubler (citado por Gumicio, 2000) ofrece una segunda e interesante clasificación de este sector desprotegido o con una protección degradada e insuficiente; en "grupos marginales de la empresa", los que son subordinados; $y$, aquellos que trabajan sin relación laboral. En la primera categoría incluye a los trabajadores afectos a una: 1) Contratación temporal. 2) A un trabajo a tiempo parcial. 3) A un trabajo cedido a terceros (es el caso de las empresas de suministro de personal o empresas de trabajo temporal) y; 4) El trabajo "clandestino", sea por simulación jurídica de una relación distinta, sea por simple infracción a la norma laboral.

En el segundo grupo, el de los trabajadores independientes, incluye: 1) A los "cuasi trabajadores," los que están entre la dependencia y la autonomía plena. 2) Los trabajadores a domicilio. 3) Los colaboradores libres (free lance). 4) Vendedores o agentes de intermediación. 5) Nuevas formas de trabajo autónomo, enlazados a la cadena de producción de la empresa (subcontratación), como ocurre con el teletrabajo y otros mini empresarios que son subcontratados para tareas antes cubiertas por asalariados. 6) Los trabajadores familiares; y 7) Los trabajadores asociados a cooperativas.

Rasgos comunes que aparecen en muchas de estas categorías de trabajadores asalariados o autónomos, son: La carencia de ingresos regulares; la infor- 
malidad en el registro de su situación jurídica laboral; la dependencia económica; y un nivel de protección social mínimo o inexistente. Obsérvese que muchos de ellos registran una relación subordinada que debería incorporarlos automáticamente al estatuto protector, propio de los trabajadores por cuenta ajena, sin embargo, lo característico de estos grupos es precisamente, la informalidad de su registro laboral y la inadecuación de su realidad a las exigencias de acceso a los programas de seguridad social contributivos.

Es cierto que la naturaleza de la labor demarca con facilidad el trabajo autónomo. La pericia para realizarlo, el arte del oficio o el saber para ejecutarlo; es propio de una labor prestada libremente. El independiente es para quien lo contrata, un auxiliar profesional, es un productor de conocimiento o un experto en su oficio. Este trabajador autónomo, es un agente característico de la sociedad urbana y mercantil; es un tipo de trabajador formado para y por la práctica de un oficio hecho escuela. Pero ha sido la necesidad y la carencia de contratos estables, las que han hecho emerger el trabajo independiente, que se desliza masivamente hacia la informalidad y pierde potenciales beneficios previsionales, y es que ante un estatuto tradicional de contenido progresivo, considerado como típico en las legislaciones sociales, surge un autónomo de bajos ingresos y calificación (Garro, 2003).

Son pocas las excepciones que rompen la regla de la desprotección: Existe una en el Reino Unido con vendedores de periódicos de calle, organizados después en una veintena de países y que ofrecen alrededor de 25 millones de ejemplares al año, lo que sería denomi- nado por Aguirre (2002) como "la transnacional de los pobres." Los proveedores -indigentes-, se benefician del producto de las ventas y reciben apoyo médico y legal de la red. Pero en términos generales, las dificultades son las que sobresalen, debido a (Montoya Melgar citado por Gumucio, 2000: 20).

La dispersión local de los trabajadores autónomos, lo que obstaculiza severamente la determinación de las bases de cotización, y la extrema gravedad que encierra la ausencia -y casi imposibilidadde un adecuado sistema de fiscalización y control; dificulta el cálculo actuarial e incrementa las posibilidades de fraude.

La ausencia del binomio empresario-trabajador sobre el que descansa el esquema jurídico de los seguros sociales, contribuye a agravar la retención de las cotizaciones y aumentar su precio. Normalmente, los trabajadores deben asumir la cuota parte que le correspondería pagar por un empleador que jurídicamente no poseen.

El débil o nulo poder de presión de los independientes sobre el Poder Público para lograr la inserción en el ámbito de la seguridad social o para mejorar la calidad de la protección; coadyuva a que los gobiernos no reglamenten el trabajo independiente.

Y por último, persiste la resistencia a incluirlos en algunos seguros como el de desempleo; por la difícil comprobación de la cesantía, y en el de accidentes del trabajo y enfermedades profesionales; por estar fundado en la existencia del contrato de trabajo.

\section{La uniforme respuesta: El ahorro obligatorio}

Ante el inevitable envejecimiento demográfico y un mercado de trabajo con 
menos activos, en la última década se ha puesto el acento en revisar los métodos de financiamiento, procurando aumentar el ahorro de la población trabajadora, incluida la autónoma, o apostando al empleo de la mayor cantidad de personas disponibles. Es un debate que ha involucrado a casi todos los países de la región, los que han elegido mayoritariamente la opción del ahorro obligatorio para capitalizar sus prestaciones, lo cual es estimulado principalmente por y desde los organismos multilaterales de crédito ${ }^{7}$.

La alternativa del ahorro obligatorio, tiene algunas limitaciones en lo que respecta a la protección de los autónomos (los que son ahora preocupación de la gerencia privada, a la que se le da oportunidad de administrar este espacio que antes le era vedado), así por ejemplo, la
Federación Internacional de Administradoras de Fondos de Pensiones (FIAP), ofrece algunas estadísticas del año 2002 donde se observa la relación entre afiliados (registrados) y cotizantes (contribuyentes regulares), reflejando, pese a la intervención privada, la baja cobertura. Tal como se evidencia en la Tabla 1.

La última columna (no incluye a Costa Rica), indica la población regular cotizante, la que no varía pese a estructuras administrativas y demográficas distintas, como si hubiese un tope, puesto por la economía informal, el desempleo y los bajos salarios, y cuando ello mejora, es por la concentración de la clientela en pocas manos, como sucede en el caso Boliviano, donde 2 administradoras tienen el monopolio exclusivo del país (se espera por una tercera de capital venezolano).

\section{Tabla 1. Relación de cotizantes}

\begin{tabular}{lccccc}
\hline Países & $\begin{array}{c}\text { Fondos en } \\
\text { relación al PBI }\end{array}$ & PEA & Afiliados & Cotizantes & $\begin{array}{c}\text { Afiliado/ } \\
\text { Cotizante }\end{array}$ \\
\hline Argentina & 7,16 & 13.698 .000 & 8.498 .249 & 3.420 .852 & $40,3 \%$ \\
Bolivia & 10,12 & 3.000 .000 & 633.152 & 587.873 & $92,8 \%$ \\
Chile & 51,08 & 5.857 .030 & 6.308 .001 & 3.201 .809 & $50,8 \%$ \\
Colombia & 6,17 & 19.554 .000 & 4.038 .320 & 1.658 .270 & $41,1 \%$ \\
Costa Rica & 1,98 & 1.319 .000 & 832.976 & $\mathrm{n} / \mathrm{d}$ & \\
El Salvador & 4,44 & 2.522 .300 & 877.920 & 493.206 & $56,2 \%$ \\
México & 3,46 & 39.507 .063 & 18.444 .190 & 10.609 .011 & $57,5 \%$ \\
Perú & 5,56 & 11.400 .000 & 2.525 .103 & 1.025 .098 & $40,6 \%$ \\
Uruguay & 4,28 & 1.230 .614 & 581.800 & 305.073 & $52,4 \%$ \\
Total & 7,79 & 98.088 .007 & 42.739 .711 & 21.301 .192 & $50,8 \%$ \\
\hline
\end{tabular}

Fuente: FIAP, 2002.

7 Después de Chile (1980-81), los países que emprendieron reformas radicales en sus sistemas previsionales en los 90 fueron: Perú (1992); Colombia (1993); Argentina (1994); Bolivia, Uruguay y el Salvador (1996); México (1997). Luego han seguido, entre el 2000 y el 2002; Nicaragua, Costa Rica y República Dominicana. Disponible (OISS,2004). 
Las diferencias son mayores aún, cuando se compara la PEA y la relación afiliado/cotizante.

La experiencia chilena, de acuerdo a Gumucio (2000:23), es paradigmática en este punto: Las cifras dan cuenta del absoluto fracaso de este modelo, así, para Febrero de 2000, el conjunto de las Administradoras de Fondos de Pensiones (AFP) registraban un total de 64.317 cotizantes independientes, representando apenas alrededor del 7, 5\% de la masa del total de autónomos.

Aparte, el problema del costo, por ejemplo, las Administradoras de Fondos de Retiro mexicanas (AFORES), estiman que sus 30 millones de afiliados deben realizar aportaciones voluntarias adicionales equivalentes a por lo menos el 20 por ciento de su salario actual, para así poder gozar de un retiro digno. Ello ocurre, porque el sistema garantiza una tasa de retorno de apenas 40 por ciento del último salario del trabajador. Lamentablemente, informaron, las tablas actuariales que se usaron para las Afores hace nueve años "ya no valen: fueron mal calculadas" (Leal, 2004).

\section{La intervención pública en el bienestar colectivo}

Los pocos Estados que han preferido impulsar reformas públicas sin recurrir al expediente de la privatización, no han obtenido sin embargo mejores resultados (Castro Gutiérrez, 2003). Así que aparte de la necesidad de ponerse de acuerdo con una opción financiera efectiva para aumentar la producción de bienes y servicios; hay que poner en juego otros medios, entre los que destacan los gerenciales, ello, no es una cuestión fácil de reali- zar, sino se tiene antes el panorama de acción suficientemente claro. Es necesario en consecuencia interiorizar una estrategia que reconozca.

En primer lugar, aparte e independiente a la participación privada, es la pública, la puede ampliar el pre-financiamiento; mejorar la calidad del empleo con mínimos estandarizados; y optimizar, -como apunta Barr (2002)-, las deudas, cuando no exista necesidad de devolverlas en lo inmediato. Es en resumen, la gerencia pública, la que puede aumentar la posibilidad de que los trabajadores autónomos sean contenidos.

En segundo lugar, sabemos que el principal cuestionamiento que se le hace a la gerencia pública, es su falta de eficiencia en el gasto y el uso de los tiempos de ejecución, tantas veces diferidos o incumplidos, pero es incuestionable su innata capacidad para administrar los medios de aumento del bienestar colectivo, siempre que logre inter- relacionar a los miembros de la comunidad; concurran metas y plazos razonables de cumplimiento; exista una justa distribución de las cargas; y se provea de la misma oportunidad para consumir.

En tercer lugar, hay que tener claro que la solución a la precariedad se encuentra en la generación de empleo, posible con el crecimiento económico, sostenido y diversificado; con la garantía de un sistema judicial rápido, eficaz y gratuito; y costos accesibles de impuestos aduanales, de renta $y$ consumo que favorezcan el registro e instalación de industrias y comercios.

$Y$ en cuarto lugar, reconocer que la administración del trabajo podría utilizar sus recursos, limitados ciertamente, de manera más eficaz. En este sentido, habría que ade- 
cuar el plan ministerial a procesos de evaluación de rendimiento, lo que no es un imposible, así por ejemplo, el Ministerio de Desarrollo de Recursos Humanos de Canadá, responsable del seguro de desempleo y pensiones, entre otros programas y servicios sociales, calcula los costos de unidad que representa el pago de un cliente y el mantenimiento de los pagos realizados a éste; los de las llamadas telefónicas; cuántas solicitudes de información por correo electrónico pueden tramitarse por persona al día; elabora encuestas públicas y de personal, en fin, se trata de confeccionar indicadores de gestión, convertidos en indicadores de éxito que puedan confirmarse (Scotti, 2003), lo que por lo demás está muy extendido en Europa, los EEUU, Australia y Nueva Zelanda (Mascareño, 2003).

Después, es necesario ejecutar las siguientes tareas:

1. Necesaria es la descentralización de las funciones de empleo, la de microcréditos y la asistencia médica. No es posible ser eficientes en la cobertura del trabajo independiente, sino se focaliza la atención, los programas nacionales suelen perder impacto en la medida que "bajan" a las regiones y son prediseñados sin tomar en cuenta el color local.

2. Luce necesario hacer amigable los procedimientos; la reducción de pasos administrativos; introducir el concepto de taquilla única; las facilidades de declaración; la eliminación de anexos y discrecionalidades, todo lo cual producirá un acercamiento del trabajador independiente o evitará su fuga.

3. La tercera tarea tiene que ver con las asociaciones con el sector privado. En este sentido, el apoyo tecnológico, comercial y publicitario, puede coadyuvar en el mejor desempeño de la administración pública. El sector privado puede convertirse en un aliado en la formación profesional para aumentar el trabajo productivo, por un lado, y por el otro, el acercamiento a su gerencia es necesario, pues la misma influye decididamente en la seguridad industrial (Ramírez Silva, 1997). Destaca asimismo, la necesidad de moderar los costos asociados al trabajo y conceder incentivos fiscales.

4. Es importante flexibilizar la incorporación de los trabajadores independientes a ciertos servicios previsionales, como por ejemplo, el seguro de salud.

5. Es importante también introducir la modalidad de la supervisión única. Consiste en la fiscalización del Estado de las condiciones de trabajo de modo integral y sobre la base de un plan rector que identifica y prioriza lo que será objeto de inspección de las condiciones y medio ambiente de laboral.

Pero no hay que negar que dichas soluciones serán meramente formales sino van acompañadas de la transferencia del diseño de las políticas públicas al colectivo (Mascareño, 2003), de lo que se ha adolecido. También, poner en práctica alguna de esas medidas, incluyendo las de tipo de gerencia por resultado, requeriría de cierto grado de consenso, pues de lo contrario el propio sistema estatal las expulsaría y en otros casos, las adaptaría a su burocracia.

\section{Conclusión}

Por la informalidad y el desarrollo de relaciones atípicas; la administración del trabajo se reduce considerablemente. El 
Ministerio del Trabajo en concreto, pierde significado social y político; pues el centro de políticas públicas se desplaza a otros programas de tipo asistencial; $y$ le es muy arduo regular y supervisar. $Y$ si es por el lado de los independientes; no tienen interés de vincularse, ubicados como están mayoritariamente en el sector informal.

Por otra parte, las mutaciones producidas en la industria y que han afectado medularmente al derecho del trabajo; de la dependencia jurídica a la independencia productiva, conmueven a su administración, la que le sirve de apoyo para sus fines de tutela.

Como la seguridad social no es un proyecto neutral, las reformas de tipo previsional han cabalgado sobre uno inspirado por las agencias internacionales de crédito, siendo parte de su contenido; ampliar la capacidad de ahorro de los Estados, pero ello no ha significado una mejora de la calidad de vida de los trabajadores autónomos. Sin embargo, los países que no acuden al expediente de la privatización, no han tenido mejor suerte, por lo que habría que reconocer que el problema no es sólo de tipo financiero sino también gerencial. Sin embargo, dicho reconocimiento no basta; la administración esta condicionada a su vez por la globalización; la crisis de lo colectivo; la falta de una agenda previsional; y la contratación de agentes periciales externos a la gerencia.

Los sindicatos en esta circunstancia deben repensar su posición, y el Estado debe reconocer su propia capacidad para administrar el plan previsional, pudiéndose listar algunas soluciones y tareas que aumentarían el instrumental de la gerencia para ampliar la cobertura del trabajo independiente, pero ello requeriría, aparte de consenso y transferencia del diseño de las políticas públicas al colectivo; superar los condicionantes antes mencionados, los que no permiten dirigir adecuadamente lo público.

\section{Bibliografía citada}

Abellán, L (2001),"Los trabajadores temporales tienen triple riesgo de accidente laboral." En: El País, edición de 03 de febrero. Madrid-España.

Aguirre, Begoña (2002), "La transnacional de los pobres." En: El País, edición de 07 de mayo. Madrid-España.

Almansa Pastor, José M (1989), Derecho de la Seguridad Social. Madrid, Editorial Tecnos (6ta. Edición), 664 p.

Barr, Nicholas (2002), "Reformas de las pensiones: mitos, verdades y opciones políticas." Revista Internacional de Seguridad Social. Vol. 55 No. 2. Ginebra, AISS.

Carballo, César (2002), "Tendencia jurisprudencial en al ámbito del derecho del trabajo (influjo sobre el costo laboral)" El costo de la regulación laboral y de las decisiones judiciales en Venezuela, Caracas, Consejo Nacional de Promoción de Inversiones (CONAPRI) y Universidad Católica Andrés Bello (UCAB), p.57-107.

Castro Gutiérrez, Alvaro (2003), "Falta de cobertura de la seguridad social." Revista Estudios de la Seguridad Social. No. 91, Buenos Aíres-Argentina, Oficina Regional de la AISS para las Américas, p. 61-71.

Congreso de la República de Venezuela (1997), Gaceta oficial extraordinaria 5152, 19 de junio 1997, Ley Orgánica del Trabajo. Imprenta Nacional. 
Córdova, Efrén (1997), "El papel de la industrialización y el principio de subordinación en la evolución de la legislación laboral." Revista Gaceta Laboral. Vol.3, No.2, Maracaibo, Universidad del Zulia (LUZ). Editorial Astro Data, p.5-21.

Federación Internacional de Administradoras de Fondos de Pensiones (FIAP) (2002), Boletín Informativo. s.e; s/f.

Garro Bordonaro, Nora (2003), "La seguridad social y el mercado laboral en América." Revista Seguridad Social. Número 240, México, Enero-Febrero, CISS, p11-26.

Gumucio Rivas, Juan (2000), "Inserción de los trabajadores autónomos en los sistemas de seguridad social." IX Encuentro de ex becarios de Bologna. Octubre. Barquisimeto, Venezuela. $35 \mathrm{p}$.

Leal, Gustavo (2004), "ISSSTE prismático." En: La Jornada. Edición de 14 de febrero, México.

Mascareño, Carlos (2003), "Las políticas públicas ante las realidades emergentes. Notas para la discusión." Cuadernos del Cendes. Año 20. No.52, Caracas, tercera época. Enero-abril. Universidad Central de Venezuela (UCV), p.1-32.

Navarro, Vicenç (2002), "Socialdemocracia sin clase trabajadora” En: EI País. Edición de 22 de mayo. Madrid, España.

Oficina Internacional del Trabajo, OIT (1999), Panorama Laboral. América Latina y el Caribe. Oficina Regional para América Latina y el Caribe. Perú.

Oficina Internacional del Trabajo, OIT (2000), Informe Sobre el trabajo en el Mundo. "La seguridad de los ingresos y la protección social en un mundo en plena y transformación" Ginebra. 339 p.

Oficina Internacional del Trabajo, OIT (2001), Panorama Laboral. América Latina y el Caribe. Oficina Regional para América Latina y el Caribe. Perú, 72 p.
Organización Iberoamericana de Seguridad Social. En: http://www.oiss.org/explorer/bissi.htm, marzo de 2004.

Ojeda Avilés, Antonio (1995), Derecho Sindical. Editorial Tecnos (7ma. Edición).Madrid, $836 \mathrm{p}$.

Oppenheimer, Walter (2002), "Blair advierte de que el Estado de bienestar no es un saco sin fondo" En: El País. Edición de 11 de junio. Madrid, España.

Presidencia de la República (1999), Reglamento de la Ley Orgánica del Trabajo. Decreto No. 3.235 de 20 de enero.

Ramírez Silva, Alberto (1.997), "El rol de la gerencia en la seguridad industrial." $\mathbf{R e}$ vista Gaceta Laboral. Vol.3, No. 3, Maracaibo, Universidad del Zulia (LUZ). Editorial Astro Data, p.5-19.

Raso Delgue, Juan (2003), La contratación atípica del trabajo. Montevideo-Uruguay, Editorial y Librería Jurídica Amalio M. Fernández, p. 301.

Sarfati, Hedva (2003), "Reform through Dialogue? New Modes of Regulation for Changing Labour Market and Social Protection Systems". En: IIRA 13th World Congress, Berlin.

Scotti, Susan (2003), "Evaluación del rendimiento en las instituciones de seguridad social." Revista Estudios de la Seguridad Social. No. 92, Buenos Aíres-Argentina, Oficina Regional de la AISS para las Américas, p. 43-65.

Vargas Hernández; José Guadalupe (2001), "Los retos del Estado Latinoamericano en el nuevo milenio." Revista Ciencias de Gobierno. Instituto Zuliano de Estudios Políticos, Económicos y Sociales. Año 5. No. 9, enero-junio, p.15-55.

Verstraeten, Johan (2002), "Discurso del Presidente de la AISS en la 27 Asamblea General." Revista Estudios de la Seguridad Social. No.90, Buenos Aíres-Argentina, Oficina Regional de la AISS para las Américas, p.69-86. 